\title{
Genetic structure of the threatened
}

\section{Dipterocarpus costatus populations in lowland tropical rainforests of southern Vietnam}

\author{
N.M. Duc ${ }^{1}$, V.D. Duy ${ }^{2}$, B.T.T. Xuan ${ }^{1}$, B.V. Thang ${ }^{3}$, N.T.H. Ha ${ }^{3}$ and N.M. Tam ${ }^{2}$ \\ ${ }^{1}$ Institute of Ecology and Biological Resources, \\ Vietnam Academy of Science and Technology (VAST), Cau Giay, Hanoi, \\ Vietnam \\ ${ }^{2}$ Vietnam National Museum of Nature (VAST), Cau Giay, Hanoi, Vietnam \\ ${ }^{3}$ College of Forestry Biotechnology, Vietnam Forestry University, Xuan Mai, \\ Chuong My, Hanoi, Vietnam \\ Corresponding author: N.M. Tam \\ E-mail: ngtam@hn.vnn.vn
}

Genet. Mol. Res. 15 (4): gmr15048821

Received May 18, 2016

Accepted August 8, 2016

Published October 24, 2016

DOI http://dx.doi.org/10.4238/gmr15048821

Copyright (C) 2016 The Authors. This is an open-access article distributed under the terms of the Creative Commons Attribution ShareAlike (CC BY-SA) 4.0 License.

\begin{abstract}
Dipterocarpus costatus is an endangered species restricted to the lowland forests of southern Vietnam. Habitat loss and over-exploitation of $D$. costatus wood are the major threats to this species. We investigated the level of genetic variability within and among populations of $D$. costatus in order to provide guidelines for the conservation, management, and restoration of this species to the Forest Protection Department, Vietnam. Nine microsatellite markers were used to analyze 114 samples from four populations representing the natural range of $D$. costatus in southeast Vietnam. We indicated the low allelic diversity $\left(N_{\mathrm{A}}=2.3\right)$ and low genetic diversities with an average observed and expected heterozygosity of 0.130 and 0.151 ,
\end{abstract}


respectively, in the lowland forests of southeast Vietnam. The low genetic diversity might be a consequence of inbreeding within the small and isolated populations of $D$. costatus owing to its habitat loss and over-exploitation. All populations deviated from Hardy-Weinberg equilibrium showing reduced heterozygosity. Alleles were lost from the populations by genetic drift. Genetic differentiation among populations was high (average pairwise $F_{\mathrm{ST}}=0.405$ ), indicating low gene flow $(<1)$ and isolated populations due to its destructed habitat and large geographical distances $(\mathrm{P}<0.05)$ among populations. Heterozygosity excess tests (except of Bu Gia Map only under infinite allele model) were negative. The high genetic variation $(62.7 \%)$ was found within populations. The STRUCTURE and neighbor joining tree results suggest strong differentiation among $D$. costatus populations, with the three genetic clusters, Phu Quoc, Tan Phu and Bu Gia Map, and Lo Go-Xa Mat due to habitat fragmentation and isolation. The threatened status of $D$. costatus was related to a lack of genetic diversity, with all its populations isolated in small forest patches. We recommend the establishment of an ex situ conservation site for $D$. costatus with a new big population comprising all genetic groups in order to enhance its survival under different environmental stresses.

Key words: Dipterocarps; Dipterocarpus costatus; Genetic conservation; Genetic variability; Simple sequence repeats

\section{INTRODUCTION}

Dipterocarpus costatus is a dipterocarp restrictedly distributed in the lowland tropical forests in some provinces of southeastern Vietnam. Being an important component of semievergreen forests, it forms canopy tree communities, occasionally mixed with scattered trees of other dipterocarps, such as D. dyeri, Shorea roxburghii, S. siamensis, and Anisoptera costata on alluvial, granite, and basalt rocks in low relief areas, where water levels rise rapidly during both dry and rainy seasons. The region receives a mean annual rainfall of $2200-2500 \mathrm{~mm}$, and has annual daytime temperatures of $25^{\circ}-28^{\circ} \mathrm{C}$ and humidity of $78-83 \%$. D. costatus wood is used for general construction and ship building purposes, and its resin is used in caulking boats and preparing torches, paints, varnishes, and lacquers.

Owing to the pressure of a rapidly developing economy, D. costatus was overexploited by local people and forest enterprises in the 1980s and 1990s, leading to its habitat destruction and fragmentation. Thus, this dipterocarp is restricted to the small and isolated patches of secondary forests in protected areas such as Tan Phu rainforests (Dong Nai), Bu Gia Map National Park (Binh Phuoc), Lo Go-Xa Mat National Park (Tay Ninh), and Phu Quoc islands (Kiên Giang). D. costatus has been classified as an endangered species on the basis of the IUCN Red List Categories and Criteria version 2014.3 (Ashton, 1998). Two main threats to this dipterocarp are its limited distribution and the absence of natural regeneration. In order to conserve and manage a threatened species, it is important to understand the ecological and genetic diversity within and among populations. Various molecular markers have been identified as efficient tools for studying genetic structure, gene flow, and mating systems, and

Genetics and Molecular Research 15 (4): gmr15048821 
estimating genetic variation within a species. Especially, microsatellite markers are useful in analyzing the effective pollen flow and seed dispersal among populations and within a species (Ujino et al., 1998; Iwata et al., 2000; Takeuchi et al., 2004; Pandey and Geburek, 2009; Tam et al., 2014; Trang et al., 2014). The objective of this study was to use simple sequence repeats (SSRs) as genetic markers to investigate the level of genetic variability within and among the populations of $D$. costatus and to provide guidelines for the conservation, management, and restoration of this species to the Forest Protection Department, Vietnam.

\section{MATERIAL AND METHODS}

\section{Plant materials}

The research was carried out at four sites (Table 1). The original vegetation at these sites had been greatly affected by human activities, including agricultural expansion and overexploitation of trees for commerce, firewood collection, and construction purposes in 1980s and 1990s. However, the three-storey structure of vegetation was also found in the four studied areas. In degraded habitats, the spatial distribution and age-class structure of forest trees was altered.

\section{Table 1. Locality information for populations of Dipterocarpus costatus.}

\begin{tabular}{l|c|l|c|c|c}
\hline Population & Sample size & Locality & Altitude & Latitude & Longitude \\
\hline Tan Phu & 30 & Dinh Quan, Dong Nai Province, Vietnam & $80-120 \mathrm{~m}$ & $11^{\circ} 05^{\prime} \mathrm{N}$ & $107^{\circ} 24^{\prime} \mathrm{E}$ \\
\hline Bu Gia Map & 27 & Bu Gia Map, Binh Phuoc Province, Vietnam & $400-450 \mathrm{~m}$ & $11^{\circ} 13^{\prime} \mathrm{N}$ & $107^{\circ} 10^{\prime} \mathrm{E}$ \\
\hline Lo Go-Xa Mat & 28 & Tan Bien, Tay Ninh Province, Vietnam & $10-25 \mathrm{~m}$ & $11^{\circ} 21^{\prime} \mathrm{N}$ & $106^{\circ} 02^{\prime} \mathrm{E}$ \\
\hline Phu Quoc & 29 & Phu Quoc Islands, Kien Giang Province, Vietnam & $255 \mathrm{~m}$ & $10^{\circ} 24^{\prime} \mathrm{N}$ & $103^{\circ} 50^{\prime} \mathrm{E}$ \\
\hline
\end{tabular}

In this study, the inner barks from 114 mature trees were sampled for four populations, representing the natural range of $D$. costatus in southeastern Vietnam. The average geographical distance between the four populations was $130 \mathrm{~km}$, ranging from $55 \mathrm{~km}(\mathrm{Bu}$ Gia Map/Lo Go-Xa Mat) to $209 \mathrm{~km}$ (Phu Quoc/Tan Phu). The samples were placed in labeled plastic bags containing silica gel desiccant and transported to the laboratory for further analysis. The samples were stored at $-30^{\circ} \mathrm{C}$ until DNA extraction.

\section{DNA extraction}

DNA was extracted from the samples by using the modified cetyltrimethylammonium bromide (CTAB) method proposed by Doyle and Doyle (1987). Liquid nitrogen was added to approximately $100 \mathrm{mg}$ of each sample, which was then ground using a mixer mill MM 400 (Retsch). The total DNA concentration in each sample was determined through fluorimetry. Each DNA sample was then diluted to a concentration of $10 \mathrm{ng} / \mu \mathrm{L}$.

\section{DNA amplification for SSRs}

Nine microsatellite markers were cross-amplified for $D$. costatus to analyze the genetic diversity within and among its populations (Table 2). Six of them were isolated from D. tempehes (Isagi et al., 2002), two from Shorea curtisii (Ujino et al., 1998), and one from Dryobalonops lanceolata (Terauchi, 1994). All PCR amplifications were performed in $25-\mu \mathrm{L}$

Genetics and Molecular Research 15 (4): gmr15048821 
reaction volumes containing $10 \mathrm{ng}$ DNA template, $2 \mathrm{mM} \mathrm{MgCl}, 0.2 \mathrm{mM}$ each dNTP, 1 X PCR buffer containing Tris- $\mathrm{HCl}(10 \mathrm{mM}$ Tris- $\mathrm{HCl}, \mathrm{pH} 8.3$, and $50 \mathrm{mM} \mathrm{KCl}), 10$ pmol each forward and reverse primers, and 1.25 U Taq DNA polymerase (Invitrogen). PCRs were conducted in the GeneAmp PCR System 9700 (Applied Biosystems), under the following conditions: an initial denaturation step at $94^{\circ} \mathrm{C}$ for $2 \mathrm{~min}, 40$ cycles of $94^{\circ} \mathrm{C}$ for $1 \mathrm{~min}, 54^{\circ}$ or $56^{\circ} \mathrm{C}$ for 30 $\mathrm{s}$, and $72^{\circ} \mathrm{C}$ for $1 \mathrm{~min}$, followed by a final extension step at $72^{\circ} \mathrm{C}$ for $10 \mathrm{~min}$ to complete the extension of any remaining products before holding the samples at $4^{\circ} \mathrm{C}$ until further analysis.

Table 2. Nucleotide sequences of the simple sequence repeat primers and number of alleles for Dipterocarpus costatus.

\begin{tabular}{|c|c|c|c|c|}
\hline Primer & Nucleotide sequences $\left(5^{\prime}-3^{\prime}\right)$ & Simple sequence repeats & Number of alleles & References \\
\hline Dipt1 & $\begin{array}{l}\text { F: CTTCCCTAAATTCCCCAATGTT } \\
\text { R: TAATGGTGTGTGTACCAGGCAT }\end{array}$ & $(\mathrm{AG})_{15}$ & 3 & Isagi et al., 2002 \\
\hline$\overline{\text { Dipt3 }}$ & $\begin{array}{l}\text { F: ACAATGAAACTTGACCACCCAT } \\
\text { R: CAAAAGGACATACCAGCCTAGC }\end{array}$ & $(\mathrm{GA})_{24}$ & 4 & Isagi et al., 2002 \\
\hline Dipt4 & $\begin{array}{l}\text { F: TAGGGCATATTGCTTTCTCATC } \\
\text { R: CTTATTGCAGTCATCAAGGGAA }\end{array}$ & $(\mathrm{AG})_{15}$ & 4 & Isagi et al., 2002 \\
\hline Dipt5 & $\begin{array}{l}\text { F: TCTCAAAATCTGCAAAGACAGC } \\
\text { R: CCATAGTCATCACCTCTAATGGTC }\end{array}$ & $(\mathrm{GA})_{25}$ & 2 & Isagi et al., 2002 \\
\hline Dipt6 & $\begin{array}{l}\text { F: TGGCAAACAAGCTACTGTTCAT } \\
\text { R: CATGGGTTTAGCAACCTACACA }\end{array}$ & $(\mathrm{TA})_{8}$ & 2 & Isagi et al., 2002 \\
\hline Dipt7 & $\begin{array}{l}\text { F: CAGGAGGGGAATATGGAAAA } \\
\text { R: AAGTCGTCATCTTTGGATTGC }\end{array}$ & $(\mathrm{AC})_{9}$ & 4 & Isagi et al., 2002 \\
\hline Dipt8 & $\begin{array}{l}\text { F: ATGCTTACCACCAATGTGAATG } \\
\text { R: CTCGCAGCAGAACAACTTTCTA }\end{array}$ & $(\mathrm{GA})_{6}$ & 3 & Terauchi, 1994 \\
\hline Shc7 & $\begin{array}{l}\text { F: ATGTCCATGTTTGAGTG } \\
\text { R: CATGGACATAAGTGGAG }\end{array}$ & $(\mathrm{CT})_{8} \mathrm{CA}(\mathrm{CT})_{5} \mathrm{CACCC}(\mathrm{CTCA})_{3} \mathrm{CT}(\mathrm{CA})_{10}$ & 3 & Ujino et al., 1998 \\
\hline Shcl1 & $\begin{array}{l}\text { F: ATCTGTTCTTCTACAAGCC } \\
\text { R: TTAGAACTTGAGTCAGATC }\end{array}$ & $(\mathrm{CT})_{4} \mathrm{TT}(\mathrm{CT})_{5}$ & 2 & Ujino et al., 1998 \\
\hline
\end{tabular}

The amplification products were separated by vertical electrophoresis on $6 \%$ polyacrylamide gels in $1 \mathrm{X}$ TAE buffer $(0.04 \mathrm{M}$ Tris-acetate and $0.001 \mathrm{M}$ EDTA) and subsequently stained with ethidium bromide for 10 min using Sequi-Gen ${ }^{\circledR}$ GT (BioRad). The banding patterns were visualized under UV light and photographed using BioDocAnalyze (Biometra, Analytik Jena Company). The sizes of the PCR fragments were determined using a 25-bp DNA ladder (Invitrogen).

\section{DNA analysis}

Null alleles and allelic dropouts were determined using Micro-Checker version 2.0 (Van Oosterhout et al., 2004), at the P value equal to 0.05. GenAlex (Peakall and Smouse, 2006) was used to perform population genetic analysis and FSTAT 2.9.3 (Goudet, 2001) was used to determine the number of alleles $\left(N_{\mathrm{A}}\right)$, the number of effective alleles $\left(N_{\mathrm{E}}\right)$, and number of private alleles $\left(N_{\mathrm{P}}\right)$ per locus, observed $\left(H_{\mathrm{O}}\right)$ and expected $\left(H_{\mathrm{E}}\right)$ heterozygosities, and inbreeding coefficient $\left(F_{\text {IS }}\right)$. The tests for deviations from Hardy-Weinberg equilibrium for each locus within each population were carried out by estimating $F_{\text {IS }}$ values within 720 randomizations and linkage disequilibrium between the pairs of loci in each population was estimated using FSTAT 2.9.3. Hierarchical genetic variation, including intra-population inbreeding coefficient $\left(F_{\text {IS }}\right)$ and inter-population genetic differentiation coefficient $\left(F_{\mathrm{ST}}\right)$ among populations, was also calculated using FSTAT. The correction between the matrix of genetic distances expressed as $F_{\mathrm{ST}} /\left(1-F_{\mathrm{ST}}\right)$ and the matrix of geographical distances among populations was performed using a Mantel test with 1000 randomizations utilizing the FSTAT

Genetics and Molecular Research 15 (4): gmr15048821 
software. Arlequin was used to calculate the multilocus pairwise $F_{\mathrm{ST}}$ between different populations (Excoffier et al., 2007). The significance of variance components in analysis of molecular variance (AMOVA) was tested using 1000 permutations. The neighborjoining cluster analysis of Nei's chord distance (Nei et al., 1983) was used to determine the genetic association among populations by using POPTREE2 (Takezaki et al., 2010). A Bayesian clustering approach was implemented to investigate the population structure using STRUCTURE ver. 2.3.4 (Pritchard et al., 2000). Setting the admixture model with correlated allele frequencies, five separate runs of the number of groups in the dataset $(\mathrm{K}$ $=1-15$ ) were performed with a burn-in period of 50,000 iterations, followed by 100,000 Markov chain Monte Carlo repetitions. In order to determine the optimal value of $K$, the number of groups that best fits the dataset $(\Delta \mathrm{K})$ was determined as described by Evanno et al. (2005) using the Structure Harvester (Earl and von-Holdt, 2012). The bottleneck events for each population were tested via the infinite allele model (IAM) and two-phase model ( $95 \%$ stepwise mutation model with 5\% multi-step mutations and a variance among multiple steps of 12) using BOTTLENECK ver. 1.2 (Piry et al., 1999). The Wilcoxon signed-rank test (Luikart et al., 1998) with default execution settings was used to evaluate any deviation from 50:50 heterozygosity deficiency/excess.

\section{RESULTS}

\section{Genetic diversity}

No evidence of null alleles and allelic dropouts was found using the MicroChecker software. Four alleles were revealed at three loci (Dipt3, Dipt4, and Dipt7); three alleles at three loci (Dipt1, Dipt8, and Shc7); and two alleles at three loci (Dipt5, Dipt6, and Shc11). A total of 27 alleles were detected in D. costatus in the lowland tropical rainforests of southeast Vietnam. The largest number of alleles (4 alleles) was found at Dipt3 in the Tan Phu population (Dong Nai), Dipt4 in Lo Go-Xa Mat (Tay Ninh), and Dipt7 in Phu Quoc (Kien Giang). One allele was found at three loci (Dipt1, Dipt5, and Dipt6) in Bu Gia Map (Binh Phuoc) and two loci (Dipt5 and Dipt6) in Phu Quoc. The number of polymorphisms at all nine loci was higher in Tan Phu and Lo Go-Xa Mat (100\%) than in Phu Quoc (77.8\%) and Bu Gia Map (66.7\%) populations. The values of genetic diversity for $D$. costatus populations are presented in Table 3 . The $N_{\mathrm{A}}$ in different populations ranged from 1.8 to 2.6, with an average of 2.3. The $N_{\mathrm{E}}$ ranged from 1.1 to 1.2 , with an average of 1.2. The $N_{\mathrm{p}}$ was found at Dipt3 (allelic frequencies $=0.017$ ) in Tan Phu, Dipt7 (0.052) in Phu Quoc, Dipt1 (0.071), and Dipt4 (0.036) in Lo Go-Xa Mat. The average $N_{\mathrm{p}}$ was 0.11 in Tan Phu and Phu Quoc, and 0.22 in Lo Go-Xa Mat. The highest values for $H_{\mathrm{O}}=0.152$ and $H_{\mathrm{E}}=0.174$ were detected in Tan Phu. In all the studied populations, there were positive fixation index values, indicating an excess of homozygotes and inbreeding. The inbreeding coefficient was the lowest $\left(F_{\text {IS }}=0.071, \mathrm{P}=0.053\right)$ in Bu Gia Map and the highest $\left(F_{\text {IS }}=0.135, \mathrm{P}=0.0 .34\right)$ in Lo Go-Xa Mat. AMOVA results showed that the genetic variation within populations $(62.7 \%$; $\mathrm{P}<0.001)$ was high compared to that among the four populations (37.3\%). The heterozygosity excess was detected in all four populations using the three models $(\mathrm{P}<0.05)$, except for Bu Gia Map using IAM $(\mathrm{P}=$ 0.109). The mode shift did not detect any evidence of a bottleneck.

Genetics and Molecular Research 15 (4): gmr15048821 
Table 3. Genetic variation within Dipterocarpus costatus populations at nine SSR loci.

\begin{tabular}{l|c|c|c|c|c|c|c}
\hline Population & $\mathrm{N}$ & $N_{\mathrm{A}}$ & $N_{\mathrm{E}}$ & $N_{\mathrm{P}}$ & $H_{\mathrm{O}}$ & $H_{\mathrm{E}}$ & $F_{\mathrm{IS}}$ \\
\hline Tan Phu & 30 & 2.56 & 1.21 & 0.11 & 0.152 & 0.174 & 0.104 \\
\hline Bu Gia Map & 27 & 1.78 & 1.14 & - & 0.099 & 0.110 & 0.071 \\
\hline Lo Go-Xa Mat & 28 & 2.56 & 1.20 & 0.22 & 0.143 & 0.166 & $0.135^{*}$ \\
\hline Phu Quoc & 29 & 2.22 & 1.20 & 0.11 & 0.126 & 0.152 & $0.106^{*}$ \\
\hline Mean & & 2.27 & 1.19 & & 0.130 & 0.151 & 0.107 \\
\hline
\end{tabular}

$\mathrm{N}$, number of collected samples; $N_{\mathrm{A}}$, mean number of alleles per locus; $N_{\mathrm{E}}$, number of effective alleles; $N_{\mathrm{p}}$, number of private alleles; $H_{\mathrm{O}}$ and $H_{\mathrm{E}}$, mean observed and expected heterozygosities, respectively; $F_{\mathrm{IS}}$, Wright's inbreeding coefficient. ${ }^{*} \mathrm{P}<0.05$.

\section{Population structure}

Analyses of genetic divergence among populations indicated that all four populations were significantly differentiated $(\mathrm{P}<0.05$; Table 4$) . F_{\mathrm{ST}}$ values ranged from 0.315 to 0.481 , with an average of 0.405 and the value of gene flow $\left(N_{\mathrm{m}}\right)$ was 0.37 . The largest genetic distance (0.303) was found between the populations of Lo Go-Xa Mat and Phu Quoc, and the smallest (0.082) between the populations of Bu Gia Map and Lo Go-Xa Mat, with an average of 0.180. Similar results were found for genetic identity; the largest identity (0.921) between Lo Go-Xa Mat and Bu Gia Map and the smallest (0.739) between Phu Quoc and Lo Go-Xa Mat, with an average of 0.837 . The obtained value of genetic distance indicated high level of differentiation between Phu Quoc and the remaining populations (Tan Phu, Lo Go-Xa Mat, and Bu Gia Map). According to Mantel, the significant correlation was found between the pairwise $F_{\mathrm{ST}}$ values $\left(F_{\mathrm{ST}} /\left(1-F_{\mathrm{ST}}\right)\right.$ and the geographic distance between the populations $(\mathrm{r}=0.653, \mathrm{P}<0.05)$.

Table 4. Pairwise $F_{\mathrm{ST}}$ values and significant $\mathrm{P}$ values $(\mathrm{P}=0.05)$ in Dipterocarpus costatus populations.

\begin{tabular}{l|c|c|c|c}
\hline Population & Tan Phu & Bu Gia Map & Lo Go-Xa Mat & Phu Quoc \\
\hline Tan Phu & & + & + & + \\
\hline Bu Gia Map & 0.402 & & + & + \\
\hline Lo Go-Xa Mat & 0.321 & 0.315 & & + \\
\hline Phu Quoc & 0.481 & 0.438 & 0.477 & \\
\hline
\end{tabular}

The population genetic relationship based on Nei's chord distance and the Bayesian analysis, implemented in STRUCTURE, indicated through a bar plot that the most likely number of genetic clusters was $3(\Delta \mathrm{k}=150)$. These results were consistent with the evidence that individuals with similar multilocus genotypes were assigned distinct populations (Figures 1 and 2). Most of the individuals at Tan Phu and Phu Quoc were detected with two distinct clusters. However, there was a little signal of admixture in these populations. The third cluster was composed of two populations - Bu Gia Map (Binh Phuoc) and Lo Go-Xa Mat (Tay Ninh). Some individuals of the Tan Phu population belong to $\mathrm{Bu}$ Gia Map and Lo Go-Xa Mat, indicating admixture of populations due to gene flow in the past. In the $1800 \mathrm{~s}$, the large habitat of $D$. costatus in the southeastern region of Vietnam included all three Provinces of Dong Nai, Binh Phuoc, and Tay Ninh. The STRUCTURE results suggest distinct differentiation among D. costatus populations due to habitat fragmentation and isolation.

Genetics and Molecular Research 15 (4): gmr15048821 


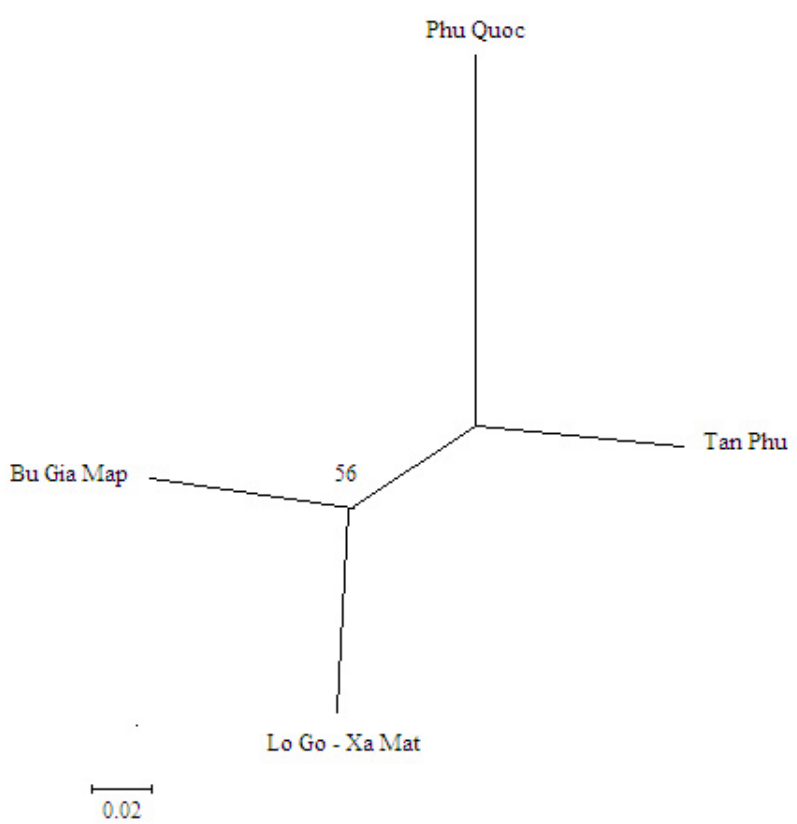

Figure 1. Neighbor joining tree of 4 populations based on Nei's chord distance.

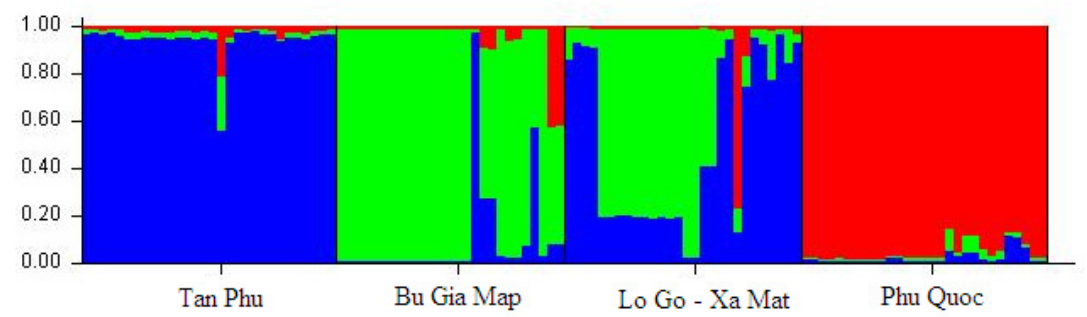

Figure 2. Bar plot of admixture assignment for four populations to the clusters $(K=3)$ based on Bayesian analysis.

\section{DISCUSSION}

The results obtained in the present study indicated that the studied populations of D. costatus in the lowland forests of southeastern Vietnam retained the low allelic diversity $\left(N_{\mathrm{A}}=2.3, N_{\mathrm{E}}=1.2\right)$ and low genetic diversities with $H_{\mathrm{O}}$ and $H_{\mathrm{E}}$ of $0.130(0.099-0.152)$ and $0.151(0.110-0.174)$, respectively. The observed allelic diversity was low compared to Shorea leprosula $\left(N_{\mathrm{A}}=11.0-11.4 ; \mathrm{Ng}\right.$ et al., 2004) and Dryobalanops aromatica $\left(N_{\mathrm{A}}=5.1\right.$; Lim et al., 2001). Besides, these were compared to the $H_{\mathrm{O}}$ and $H_{\mathrm{E}}$ values that had been reported from other dipterocarp species such as $S$. leprosula $\left(H_{\mathrm{O}}=0.63-0.66, H_{\mathrm{E}}=0.69-0.71 ; \mathrm{Ng}\right.$ et al., 2004), Parashorea malaanonan $\left(H_{\mathrm{O}}=0.26, H_{\mathrm{E}}=0.46\right.$; Abasolo et al., 2009), Hopea odorata $\left(H_{\mathrm{O}}=0.366, H_{\mathrm{E}}=0.356\right.$; Trang et al., 2014), and D. alatus $\left(H_{\mathrm{O}}=0.209, H_{\mathrm{E}}=0.239\right.$; Tam et al., 2014). Therefore, the low genetic diversities might be a consequence of allelic loss within the populations of $D$. costatus. Moreover, the STRUCTURE analysis showed that the 
two populations, Tan Phu and Phu Quoc, were genetically separated, with a little signal of admixture. However, the admixture of the Tan Phu population with the Bu Gia Map and Lo Go-Xa Mat populations was 10 and 51\%, respectively. The Phu Quoc population was isolated from the remaining populations, suggesting a restricted dispersal among them owing to the large geographical distances of $180 \mathrm{~km}(126-209 \mathrm{~km})$ between them. The Tan Phu, Bu Gia Map, and Lo Go-Xa Mat populations were distributed in southeast Vietnam. Historically, this region was covered by a large natural forest, where D. costatus occurred. The destruction of this forest for agricultural purposes and urbanization led to its fragmentation. Moreover, in 1980s and 1990s, the over-exploitation of forests still continued. Thus, the deforestation, habitat degradation, and over-exploitation of $D$. costatus for commerce (wood and aromatic oily resin) are the major factors that might explain the low heterozygosity values that were found in all the studied populations. The fixation of alleles at the three loci (Dipt1, Dipt5, and Dipt7) for Bu Gia Map and two loci (Dipt5 and Dipt6) for Phu Quoc might explain the low heterozygosity values for this dipterocarp species. This might result from the significantly decreased size of the D. costatus populations confined to the small patches in the secondary forest remnants. Clearly, the small population sizes might affect the number of alleles in the studied populations. The occurrence of small and isolated populations for many generations can lead to inbreeding and loss of alleles within the populations by genetic drift. The mean deficit of heterozygote $\left(F_{\text {IS }}=0.107\right)$ estimated for the four populations indicated inbreeding due to selfing or biparental mating. The significantly positive $F_{\text {IS }}$ values of 0.135 and 0.106 were found in Lo Go-Xa Mat and Phu Quoc, respectively $(\mathrm{P}<0.05)$. Consequently, the inbreeding coefficient and homozygosity decreased the number of alleles in the $D$. costatus populations.

The results of AMOVA showed $62.7 \%$ genetic variance within the populations, whereas $37.3 \%$ variance was found among the populations. This level of genetic variation was considered high when compared to Shorea species in Indonesia with a $43 \%$ genetic variation within populations (Cao et al., 2009), and low when compared to D. alatus in Vietnam with a genetic variation of $74.9 \%$ within populations and the genetic differentiation of 0.266 (Tam et al., 2014). The high values of pairwise $F_{\mathrm{ST}}(0.405)$ showed strong differentiation among the $D$. costatus populations. Due to large geographical distances between the populations $(>50 \mathrm{~km})$, the limited gene flow via pollen (pollination by insects within a distance of $200 \mathrm{~m}$; Appanah and Chan, 1981; Fukue et al., 2007) and seed dispersal by wind or gravity (the dispersal distances of up to $500 \mathrm{~m}$; Chan, 1980; Takeuchi et al., 2004). The analysis also revealed the low levels of migration among the studied populations $\left(N_{\mathrm{m}}=0.37\right)$. Thus, the level of genetic diversity as well as the mixture of ancestral alleles of the genetic groups were observed in the bar plot. However, these groups were formed with individuals from the genetic clusters comprising the four populations. These results showed low levels of gene flow $\left(N_{\mathrm{m}}<1\right)$ among populations. A barrier to gene flow was reflected by significant differentiation $(\mathrm{P}<0.001)$ in D. costatus.

In conclusion, the low levels of genetic variability and the high levels of genetic differentiation observed within the $D$. costatus populations are the consequence of human interferences and large geographical distances among them. In the recent decades, the overexploitation of $D$. costatus wood and aromatic oily resin for commercial purposes has greatly destroyed its habitat. All studied populations were confined to small forest patches that were separated by the large geographical distances. The habitat degradation and narrow distribution of $D$. costatus have led to its endangerment. Therefore, it is considered as a priority species for conservation in Vietnam. The results obtained in this study suggest that the threatened status of D. costatus was related to the lack of genetic diversity. Thus, the best conservation strategy for

Genetics and Molecular Research 15 (4): gmr15048821 
this species is to establish an ex situ conservation site using seeds collected from individuals of all populations of $D$. costatus, thereby avoiding the random loss of genetic variability due to the loss of individual ecotypes and enhancing the survival of new self-sustaining populations. The establishment of a new big population of $D$. costatus should provide new alleles, which might improve its fitness under different environmental stresses.

\section{ACKNOWLEDGMENTS}

Research supported by grant provided to M.D. Nguyen (\#VAST.BVMT.01/15-16; Grantee D/5766-1).

\section{REFERENCES}

Abasolo M, Fernando ES, Borromeo TH and Hautea DM (2009). Cross-species amplification of Shorea microsatellite DNA markers in Parashorea malaanonan (Dipterocarpaceae). Philipp. J. Sci. 138: 23-28.

Appanah S and Chan HT (1981). Thrips: the pollinators of some dipterocarps. Malaysia For. 44: 234-252.

Ashton P (1998). The IUCN red list of threatened species. Version 2014.3.

Cao CP, Gailing O, Siregar IZ, Siregar UJ, et al. (2009). Genetic variation in nine Shorea species (Dipterocarpaceae) in Indonesia by AFLPs. Tree Genet. Genomes 5: 407-420. http://dx.doi.org/10.1007/s11295-008-0195-4

Chan HT (1980). Reproductive biology of some Malaysia dipterocarps. II. Fruiting biology and seeling studies. Malay. For. 43: 438-451. 10.1007/s112954.

Doyle JJ and Doyle JL (1987). A rapid DNA isolation procedure for small qualities of fresh leaf tissue. Phytochem. Bull. 19: 11-15.

Earl DA and von-Holdt BM (2012). Structure Harvester: a website and program for visualizing structure output and implementing the Evanno method. Conserv. Genet. Resour. 4: 359-361. http://dx.doi.org/10.1007/s12686-011-9548-7

Evanno G, Regnaut S and Goudet J (2005). Detecting the number of clusters of individuals using the software STRUCTURE: a simulation study. Mol. Ecol. 14: 2611-2620.http://dx.doi.org/10.1111/j.1365-294X.2005.02553.x

Excoffier L, Laval G and Schneider S (2007). Arlequin (version 3.0): an integrated software package for population genetics data analysis. Evol. Bioinform. Online 1: 47-50.

Fukue Y, Kado T, Lee SL, Ng KK, et al. (2007). Effects of flowering tree density on the mating system and gene flow in Shorea leprosula (Dipterocarpaceae) in Peninsular Malaysia. J. Plant Res. 120: 413-420. http://dx.doi.org/10.1007/ $\underline{\text { s10265-007-0078-z }}$

Goudet J (2001). FSTAT, a program to estimate and test gene diversities and fixation indices (version 2.9.3). Available at [http://www.unil.ch/izea/softwares/fstat.html].

Isagi V, Kenta T and Nakashizuka T (2002). Microsatellite loci for a tropical emergent tree, Dipterocarpus tempehes V. S1 (Dipterocarpaceae). Mol. Ecol. Notes 2: 12-13. http://dx.doi.org/10.1046/j.1471-8286.2002.00127.x

Iwata H, Konuma A and Tsumura Y (2000). Development of microsatellite markers in the tropical tree Neobalanocarpus heimii (Dipterocarpaceae). Mol. Ecol. 9: 1684-1685.http://dx.doi.org/10.1046/j.1365-294x.2000.01058-15.x

Lim LS, Wickneswari R, Lee SL and Latiff A (2001). Genetic structure of natural populations of Dryobalanops aromatic Gaertn. F. (Dipterocarpaceae) in peninsular Malaysia using microsatellite DNA markers. In: In-situ and ex-situ conservation of commercial tropical trees (Thielges BA, Sastrapradja SD and Rimbawanto A, eds.). Gadjah Mada University, Yogyekarta, 309-324.

Luikart G, Allendorf FW, Cornuet JM and Sherwin WB (1998). Distortion of allele frequency distributions provides a test for recent population bottlenecks. J. Hered. 89: 238-247. http://dx.doi.org/10.1093/jhered/89.3.238

Nei M, Tajima F and Tateno Y (1983). Accuracy of estimated phylogenetic trees from molecular data. II. Gene frequency data. J. Mol. Evol. 19: 153-170.http://dx.doi.org/10.1007/BF02300753

Ng KK, Lee SL and Koh CL (2004). Spatial structure and genetic diversity of two tropical tree species with contrasting breeding systems and different ploidy levels. Mol. Ecol. 13: 657-669. doi: 10.1046/j.1365-294X.2004.0294.x, 1-13.

Pandey M and Geburek T (2009). Successful cross-amplification of Shorea microsatellites reveals genetic variation in the tropical tree, Shorea robusta Gaertn. Hereditas 146: 29-32. http://dx.doi.org/10.1111/j.1601-5223.2009.02070.x

Peakall R and Smouse PE (2006). Genalex 6: genetic analysis in excel. Population genetic software for teaching and research. Mol. Ecol. Notes 6: 288-295. http://dx.doi.org/10.1111/j.1471-8286.2005.01155.x

Genetics and Molecular Research 15 (4): gmr15048821 
Piry S, Luikart G and Cornuet JM (1999). BOTTLENECK: a computer program for detecting recent reductions in the effective population size using allele frequency data. J. Hered. 90: 502-503. http://dx.doi.org/10.1093/jhered/90.4.502

Pritchard JK, Stephens M and Donnelly P (2000). Inference of population structure using multilocus genotype data. Genetics 155: 945-959.

Takeuchi Y, Ichikawa S, Konuma A, Tomaru N, et al. (2004). Comparison of the fine-scale genetic structure of three dipterocarp species. Heredity 92: 323-328. http://dx.doi.org/10.1038/sj.hdy.6800411

Takezaki N, Nei M and Tamura K (2010). POPTREE2: Software for constructing population trees from allele frequency data and computing other population statistics with Windows interface. Mol. Biol. Evol. 27: 747-752. http://dx.doi. org $/ 10.1093 / \mathrm{molbev} / \mathrm{msp} 312$

Tam NM, Duy VD, Duc NM, Giap VD, et al. (2014). Genetic variation in and spatial structure of natural populations of Dipterocarpus alatus (Dipterocarpaceae) determined using single sequence repeat markers. Genet. Mol. Res. 13: 5378-5386. http://dx.doi.org/10.4238/2014.July.24.17.

Terauchi R (1994). A polymorphic microsatellite marker from the tropical tree Dryobalanops lanceolata (Dipterocarpaceae). Jpn. J. Genet. 69: 567-576. http://dx.doi.org/10.1266/jigg.69.567

Trang NTP, Huong TT, Duc NM, Sierens T, et al. (2014). Genetic population of threatened Hopea odorata Roxb. in the protected areas of Vietnam. J. Viet. Env. 6: 69-76. Doi: 10.13141/jve.

Ujino T, Kawahara T, Tsumura Y, Nagamitsu T, et al. (1998). Development and polymorphism of simple sequence repeat DNA markers for Shorea curtisii and other Dipterocarpaceae species. Heredity 81: 422-428. http://dx.doi. org/10.1046/j.1365-2540.1998.00423.x

Van Oosterhout C, Hutchinson WF, Wills DPM and Shipley DF (2004). Micro-Checker: software for identifying and correcting genotyping errors in microsatellite data. Mol. Ecol. Notes 4: 535-538. http://dx.doi.org/10.1111/j.1471$\underline{8286.2004 .00684 . x}$

Genetics and Molecular Research 15 (4): gmr15048821 